\title{
Rates of early complications and mortality in patients older than 80 years of age after surgical treatment of acute traumatic spinal fractures: ankylosing spondylitis versus osteoporosis
}

\author{
Basem Ishak, MD, ${ }^{1,2}$ Sven Frieler, MD, ${ }^{1,4}$ Tarush Rustagi, MD, ${ }^{3}$ Alexander von Glinski, MD, PhD, ${ }^{1,4}$ \\ Ronen Blecher, MD, ${ }^{1,5}$ Daniel C. Norvell, PhD, ${ }^{6}$ Andreas Unterberg, MD, PhD, ${ }^{2}$ Sarah Strot, MN, ${ }^{1}$ \\ Jeffrey Roh, MD, MSc, MBA, ${ }^{1}$ Robert A. Hart, MD, ${ }^{1}$ Rod Oskouian, MD, ${ }^{1}$ and Jens R. Chapman, MD ${ }^{1}$

\begin{abstract}
${ }^{1}$ Swedish Neuroscience Institute, Seattle; and ${ }^{6}$ Spectrum Research, Inc., Tacoma, Washington; ${ }^{2}$ Department of Neurosurgery, Heidelberg University Hospital, Heidelberg; and ${ }^{2}$ Department of Trauma Surgery, BG University Hospital Bochum, Germany; ${ }^{3}$ Indian Spinal Injuries Centre, Vasant Kunj New Delhi, Delhi, India; and ${ }^{5}$ Assuta University Hospital Ashdod, Ben Gurion University of the Negev, Israel
\end{abstract}

\begin{abstract}
OBJECTIVE The purpose of this retrospective cohort study was to analyze the early complications and mortality associated with multilevel spine surgery for unstable fractures in patients older than 80 years of age with ankylosing spondylitis and to compare the results with an age- and sex-matched cohort of patients with unstable osteoporotic fractures.

METHODS A retrospective review of the electronic medical records at a single institution was conducted between January 2014 and December 2019. Patient demographics, surgical characteristics, complications, hospital course, and 90day mortality were collected. Comorbidities were stratified using the age-adjusted Charlson Comorbidity Index (CCI).

RESULTS Among 11,361 surgically treated patients, 22 patients with ankylosing spondylitis (AS group) and 24 patients with osteoporosis (OS group) were identified. The mean ages were $83.1 \pm 3.1$ years and $83.2 \pm 2.6$ years, respectively. A significant difference in the mean $\mathrm{CCl}$ score was found (7.6 vs $5.6 ; p<0.001)$. Multilevel posterior fusion procedures were conducted in all patients, with $6.7 \pm 1.4$ fused levels in the AS group and $7.1 \pm 1.1$ levels fused in the OS group ( $p$ $>0.05$ ). Major complications developed in 10 patients (45\%) in the AS group compared with 4 patients (17\%) in the OS group ( $p<0.05)$. The 90 -day mortality was $36 \%$ in the AS group compared with $0 \%$ in the OS group $(p<0.001)$.

CONCLUSIONS Patients older than 80 years of age with AS bear a high risk of adverse events after multilevel spinal fusion procedures. The high morbidity and 90 -day mortality should be clearly discussed and carefully weighed against surgical treatment.
\end{abstract}

https://thejns.org/doi/abs/10.3171/2021.7.FOCUS21150

KEYWORDS ankylosing spondylitis; mortality; elderly; complications; comorbidity

A NKYLOSING spondylitis (AS) is a chronic, inflammatory, progressive disease that primarily affects the spinal column; its prevalence ranges between $0.1 \%$ and $1.4 \% .^{1}$ Chronic inflammation causes ossification of the facet joints, ligaments, and intervertebral discs, which limits the range of motion of the spine. This remodeling process of the vertebrae produces a classic radiographic appearance known as bamboo spine, which is often accompanied by severe kyphosis. ${ }^{2}$ The ongoing inflammatory process in the spine further leads to a rigid spinal column and high osteoclastic activity, resulting in poor bone quality that, in turn, can cause spinal frac- tures after low-energy trauma. ${ }^{3}$ Compared with a non-AS population, patients with AS have a fourfold higher risk for spinal fractures. ${ }^{4-6}$ Spinal fractures in patients with AS are often unstable due to disruption of all three columns, therefore rendering them prone to displacement. Most frequently involved are the lower cervical spine and cervicothoracic junction, followed by the thoracolumbar junction (T10-L2). ${ }^{4,7}$ With a growing elderly population due to rising life expectancy, the prevalence of patients older than 80 years of age is increasing continuously and, therefore, the incidence of AS in that age group is also increasing. ${ }^{8,9}$ Although conservative treatment can be an

ABBREVIATIONS AS = ankylosing spondylitis; $A S A=$ American Society of Anesthesiologists; $A$ SIA = American Spinal Injury Association; $C C I=$ Charlson Comorbidity Index; ICU = intensive care unit; LOS = length of stay; OS = osteoporosis.

SUBMITTED March 5, 2021. ACCEPTED July 13, 2021.

INCLUDE WHEN CITING DOI: 10.3171/2021.7.FOCUS21150. 
option for spinal fractures in AS, especially in the elderly who often suffer from several comorbidities, numerous studies have reported poor outcomes due to pulmonary complications, aspiration, worsening of kyphosis, dislocation, nonunion, and neurological decline..$^{10-12}$ Furthermore, a higher mortality in nonsurgically treated patients has been described. ${ }^{13}$ Therefore, conservative treatment of spinal fractures in patients with AS is rarely recommended, even for nondisplacement injuries without neurological impairment. Additional reasons for surgical management include greater instability, which promotes secondary fracture displacement, and patient intolerance of external bracing. ${ }^{12,14}$

Patients with AS and spinal fractures may develop higher rates of complications and mortality than patients without AS who suffer spinal fractures. ${ }^{13}$ Despite numerous case series, meta-analyses, literature reviews, and comparative cohort studies, no data regarding outcomes of surgically treated spinal fractures in patients with AS over 80 years of age exist in the current literature.

The purpose of the present study, therefore, is to analyze rates of early complications and 90-day mortality in patients with AS older than 80 years of age who received multilevel surgical treatment for unstable spinal fractures, and to compare these results to an age- and sex-matched cohort of patients without AS who received surgical treatment for unstable osteoporosis (OS).

\section{Methods}

This retrospective case-control study was approved by the IRB of Swedish Neuroscience Institute and is in accordance with the ethical standards of the 1964 Declaration of Helsinki and its later amendments..$^{15}$ We performed a review of the electronic medical records of 11,361 consecutive patients who received surgical treatment at our institution from January 2014 to December 2019. Only patients older than 80 years of age with clearly evident AS on $\mathrm{CT}$ who had been surgically treated for unstable spinal fractures ( $\mathrm{AO}$ type $\mathrm{B}$ or $\mathrm{C}$ ) were included in this study (AS group) (Fig. 1A). On CT, we defined AS as ossification of the spinal ligaments, joints, and discs with a classic appearance of a bamboo spine. ${ }^{16}$ As a control group, we chose an age-matched cohort with acute traumatic, osteoporotic, unstable, complete burst fractures (AO type A4) involving both endplates and the posterior wall (OS group) (Fig. 1B). Only patients with thoracic and thoracolumbar fractures without any other accompanying fractures or injuries were included. A Thoracolumbar Injury Classification and Severity score $\geq 4$ was necessary for both groups, and a recent bone mineral osteodensitometric examination verifying osteoporosis was necessary in the OS group. Osteoporosis was defined according to the WHO guidelines with a T-score $\leq-2.5$ measured within 1 year before surgical treatment. ${ }^{17}$ In the AS group, 7 patients (32\%) had a known history of osteoporosis. Patients with a tumor or infection were excluded. A minimum follow-up of 12 months was required for all patients. Patient demographics, BMI, comorbidities, American Society of Anesthesiologists (ASA) class, pre- and postoperative neurological status (American Spinal Injury Association

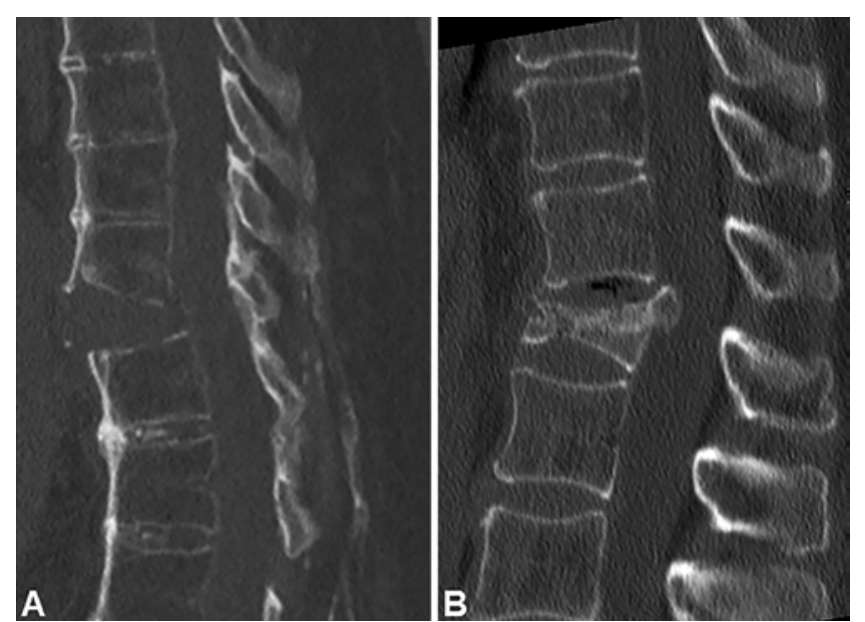

FIG. 1. A: Sagittal CT image obtained in an 84-year-old male with AS indicating a T10-11 hyperextension fracture. B: Sagittal CT scan obtained in an 82-year-old male with an acute traumatic L1 burst fracture due to osteoporosis.

[ASIA] impairment grade), duration of surgery, blood loss, number of treated spinal levels, intra- and perioperative complications, hospital length of stay (LOS), intensive care unit (ICU) stay, readmission, reoperation, and mortality were recorded. Comorbidities were preoperatively assessed based on the age-adjusted Charlson Comorbidity Index (CCI). ${ }^{18,19}$ The CCI score was calculated for each patient to classify comorbidity and grouped as having no comorbidity $(\mathrm{CCI}=0)$, minimal comorbidity $(\mathrm{CCI}=1$ or $2)$, moderate comorbidity $(\mathrm{CCI}=3-5)$, or severe comorbidity $(\mathrm{CCI}>6)$.

After retrieving the complications, we subdivided them as either major or minor. Major complications included deep surgical site infection, acute respiratory failure with unplanned reintubation, pulmonary embolism, myocardial infarction, cardiac arrest, acute heart failure, acute renal failure, gastrointestinal bleeding, and bowel perforation. Minor complications included delirium, acute encephalopathy, dysphagia, pleural effusion, pneumonia, urinary tract infection, deep vein thrombosis, ileus, and superficial wound infection.

All patients received open surgical treatment in the form of multilevel posterior spinal stabilization and decompression; removal of the epidural hematoma and laminectomy was necessary in two-thirds of the patients with AS (Fig. 2). Partial corpectomy from a posterior approach with anterior column augmentation was carried out in 3 patients in the osteoporosis control group.

\section{Statistical Analysis}

Bivariate analysis was performed to compare patients who received posterior fusion for AS with those who underwent posterior fusion for osteoporotic fractures. For categorical variables, frequency counts were computed and presented along with their percentages. For continuous variables, means were computed and presented along with their standard deviation. To compare categorical variables, the Pearson's chi-square test was used. For 
Ishak et al.

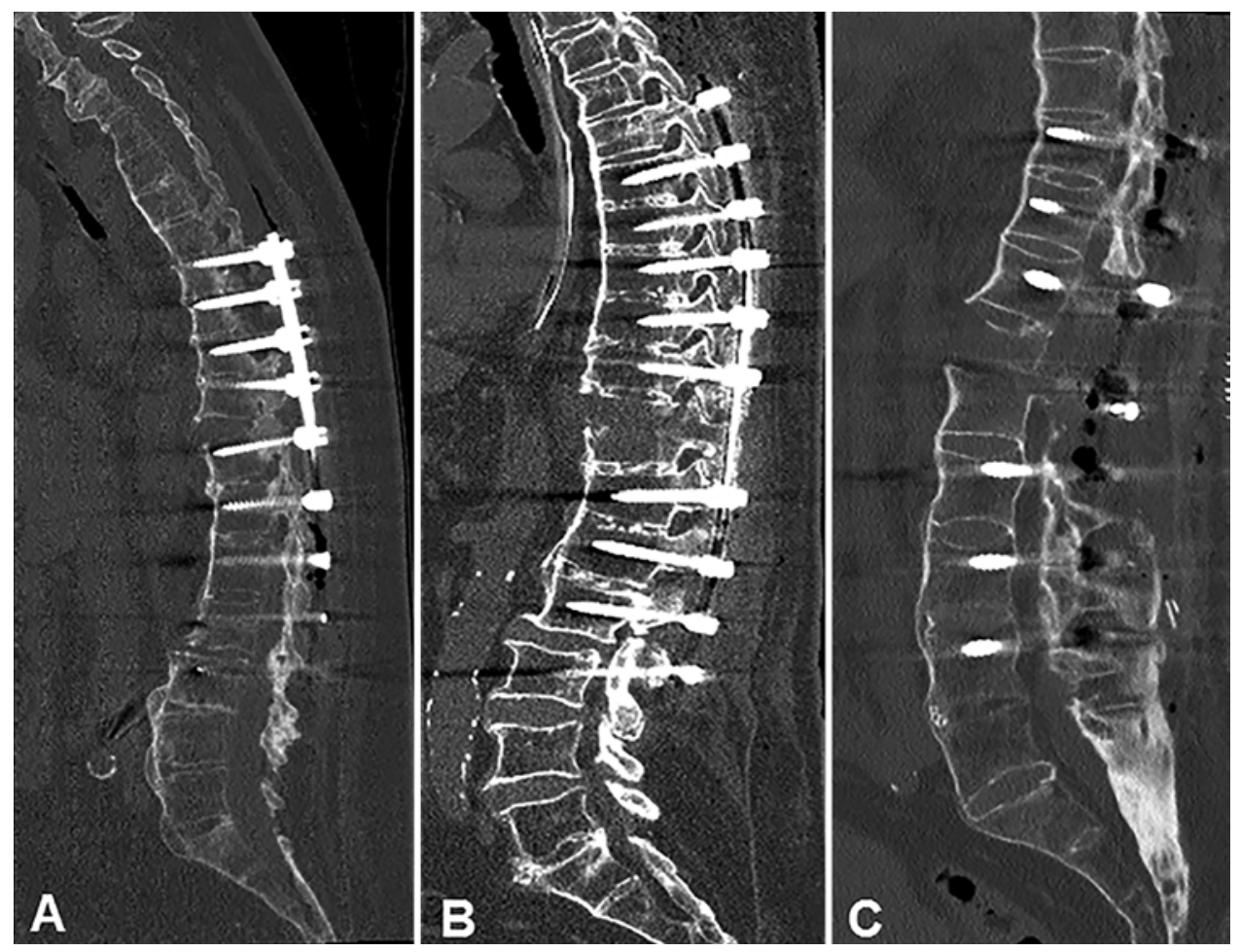

FIG. 2. Examples of postoperative sagittal CT reconstruction of patients older than 80 years of age with AS after multilevel posterior fixation. A: T7-L3. B: T5-L3. C: T10-L4.

continuous outcomes, a t-test was applied. As these procedures are so rare in patients older than 80 years of age, and our sample size was small, we were unable to perform a multivariate analysis to adjust for potential confounding. All analyses were performed using Stata version 13.1 (StataCorp LLC).

\section{Results}

The AS group included 22 male patients with a mean age of $83.1 \pm 3.1$ years (range 80-91 years) and a mean BMI of $27.5 \pm 5.7 \mathrm{~kg} / \mathrm{m}^{2}$. The OS group included 24 male patients with a mean age of $83.2 \pm 2.6$ years (range $80-91$ years) and a mean BMI of $27.2 \pm 4.7 \mathrm{~kg} / \mathrm{m}^{2}$. No significant difference in age or BMI was seen between the two groups $(\mathrm{p}>0.05)$ (Table 1).

The thoracic spine was the region most commonly fractured in the AS group, affecting 15 patients (68\%), followed by the thoracolumbar region in 7 patients $(32 \%)$ (Table 2). In the OS group, $83 \%$ of the fractures involved the thoracolumbar spine, followed by the thoracic spine at $17 \%$. No patient in this group had multilevel fractures.

\section{Mechanism of Trauma}

The most frequent mechanism of injury was a groundlevel fall in 19 patients (86\%) in the AS group and 17 patients (71\%) in the OS group. The other mechanism in the AS group was a fall downstairs in 3 patients (14\%). In the OS group, 6 patients (25\%) incurred fractures without any distinct trauma and 1 patient (4\%) reported back pain after chiropractic manipulation.
TABLE 1. Comparison of demographic parameters between the AS group and the OS group

\begin{tabular}{lccc}
\hline \multicolumn{1}{c}{ Parameter } & $\begin{array}{c}\text { AS Group } \\
(\mathrm{n}=22)\end{array}$ & $\begin{array}{c}\text { OS Group } \\
(\mathrm{n}=24)\end{array}$ & $\mathrm{p} \mathrm{Value}$ \\
\hline Mean age, yrs & $83.1 \pm 3.1$ & $83.2 \pm 2.6$ & $>0.05$ \\
\hline Male sex & $22(100)$ & $24(100)$ & $>0.05$ \\
\hline Mean BMI, kg/m ${ }^{2}$ & $27.5 \pm 5.7$ & $27.2 \pm 4.7$ & $>0.05$ \\
\hline Mean age-adjusted CCI score & $7.6 \pm 1.4$ & $5.6 \pm 1.7$ & $<0.001$ \\
\hline Cardiac disease & $14(64)$ & $5(21)$ & $<0.001$ \\
\hline Pulmonary disease & $7(32)$ & $4(17)$ & $>0.05$ \\
\hline Cerebrovascular disease & $4(18)$ & $3(13)$ & $>0.0 .5$ \\
\hline Renal disease & $6(27)$ & $1(4)$ & $>0.05$ \\
\hline Liver disease & $4(18)$ & $2(8)$ & $>0.05$ \\
\hline Malignancy & $5(23)$ & $2(8)$ & $>0.05$ \\
\hline Diabetes & $9(41)$ & $11(46)$ & $>0.05$ \\
\hline Dementia & $6(27)$ & $3(13)$ & $>0.05$ \\
\hline ASA class & & & \\
\hline II & $1(5)$ & $1(4)$ & $>0.05$ \\
\hline III & $16(73)$ & $20(83)$ & $>0.05$ \\
\hline IV & $5(23)$ & $3(13)$ & $>0.05$ \\
\hline Preop neurological deficit & $9(41)$ & $11(46)$ & $>0.05$ \\
\hline
\end{tabular}

Values are reported as number (\%) or mean \pm SD. Boldface type indicates statistical significance. 
TABLE 2. Clinical and surgical characteristics of patients with AS

\begin{tabular}{|c|c|c|c|c|c|c|c|c|}
\hline $\begin{array}{l}\text { Pt } \\
\text { No. }\end{array}$ & $\begin{array}{l}\text { Age } \\
\text { (yrs) }\end{array}$ & $\begin{array}{l}\text { Level of } \\
\text { Fracture }\end{array}$ & Surgical Treatment & $\begin{array}{c}\text { Preop ASIA } \\
\text { Grade }\end{array}$ & $\begin{array}{c}\text { ASIA Grade } \\
\text { at } 3 \text { Mos }\end{array}$ & Minor Complications & 90-Day Major Complications & $\begin{array}{c}\text { 90-Day } \\
\text { Mortality }\end{array}$ \\
\hline 1 & 87 & $\mathrm{~T} 11$ & PDF T5-L3 & $E$ & $E$ & Delirium & Bowel perforation & Yes \\
\hline 2 & 83 & $\mathrm{~L} 1$ & PDF T10-pelvis & D & $E$ & Dysphagia & Bowel perforation & Yes \\
\hline 3 & 86 & T12 & PF T8-L3 & $E$ & $E$ & None & None & None \\
\hline 4 & 80 & $\mathrm{~T} 10$ & PDF T6-L2 & $E$ & $E$ & None & None & None \\
\hline 5 & 84 & L1 & PDF T10-L3 & $E$ & $E$ & None & None & None \\
\hline 6 & 80 & $\mathrm{~T} 8 / 9$ & PDF T6-L1 & C & D & None & None & None \\
\hline 7 & 87 & L2 & PDF T12-L4 & $\mathrm{D}$ & $E$ & Pneumonia & Acute respiratory failure & Yes \\
\hline 8 & 84 & T12 & PDF T8-L4 & $E$ & $E$ & Delirium & None & None \\
\hline 9 & 82 & T11 & PDF T7-L3 & E & $\mathrm{E}$ & None & Acute renal failure & Yes \\
\hline 10 & 80 & $\mathrm{~T} 9 / 10$ & PF T7-L2 & $E$ & $E$ & Urinary tract infection & None & None \\
\hline 11 & 91 & T12 & PF T10-L2 & $E$ & $E$ & None & None & None \\
\hline 12 & 81 & T10 & PDF T7-L2 & $\mathrm{D}$ & $E$ & None & Deep wound infection & None \\
\hline 13 & 85 & $\mathrm{~L} 1 / 2$ & PDF T10-L4 & $E$ & $E$ & None & None & None \\
\hline 14 & 80 & $\mathrm{~T} 7$ & PF T3-11 & C & D & None & Gastrointestinal bleeding & Yes \\
\hline 15 & 82 & $\mathrm{~T} 9 / 10$ & PDF T6-L1 & C & $\mathrm{D}$ & None & Myocardial infarction & Yes \\
\hline 16 & 86 & T9 & PF T6-11 & $E$ & $E$ & Urinary retention & None & None \\
\hline 17 & 80 & T8 & PDF T5-10 & $E$ & $E$ & None & Myocardial infarction & Yes \\
\hline 18 & 81 & $\mathrm{~T} 11$ & PDF T7-L2 & D & $E$ & Urinary tract infection & Bowel perforation & Yes \\
\hline 19 & 87 & T6 & PDF T2-9 & $E$ & $E$ & None & None & None \\
\hline 20 & 82 & T10-11 & PDF T7-L2 & D & $E$ & Deep vein thrombosis & None & None \\
\hline 21 & 81 & T8 & PF T5-11 & C & $E$ & None & None & None \\
\hline 22 & 80 & T10 & PF T7-L1 & $E$ & $E$ & None & None & None \\
\hline
\end{tabular}

$\mathrm{PDF}=$ posterior decompression and fusion (for epidural hematoma); $\mathrm{PF}=$ posterior fusion; $\mathrm{pt}=$ patient.

\section{Scores and ASA Classifications}

The mean age-adjusted CCI score was $7.6 \pm 1.4$ for the AS group and $5.6 \pm 1.7$ for the OS group, which revealed a significant difference between the groups $(\mathrm{p}<0.001)$ (Table 1). Preoperative narcotic-relevant ASA classification revealed 1 patient (4\%) with ASA class II, 16 patients (73\%) with ASA class III, and 5 patients (23\%) with ASA class IV in the AS group. In the OS group, 1 patient (4\%) was classified as ASA class II, 20 patients (83\%) as ASA class III, and 3 patients (13\%) as ASA class IV. No significant difference was found between the groups $(p>0.05)$ (Table 1).

TABLE 3. Comparison of surgical characteristics between groups

\begin{tabular}{lccc}
\hline \multicolumn{1}{c}{ Parameter } & $\begin{array}{c}\text { AS Group } \\
(\mathrm{n}=22)\end{array}$ & $\begin{array}{c}\text { OS Group } \\
(\mathrm{n}=24)\end{array}$ & p Value \\
\hline $\begin{array}{l}\text { Mean surgical duration, } \\
\text { mins }\end{array}$ & $226.5 \pm 82.5$ & $240 \pm 51.2$ & $>0.05$ \\
\hline Mean EBL, $\mathrm{ml}$ & $584.1 \pm 196$ & $570.8 \pm 207.4$ & $>0.05$ \\
\hline Mean no. of levels fused & $6.7 \pm 1.4$ & $7.1 \pm 1.1$ & $>0.05$ \\
\hline $\begin{array}{l}\text { Intraop complications } \\
\text { (durotomy) }\end{array}$ & $3(13.6)$ & $1(4.2)$ & $>0.05$ \\
\hline
\end{tabular}

$\mathrm{EBL}=$ estimated blood loss

Values are reported as number (\%) or mean \pm SD.

\section{Neurological Deficits}

All patients presented with localized back pain (100\%). Clinical neurological deficits were found in $41 \%$ of patients in the AS group and $46 \%$ of patients in the OS group $(p>0.05)$ (Table 1). Spinal cord injury was observed in 9 patients of the AS group; 5 patients had an ASIA grade D and 4 patients had an ASIA grade C. In the OS group, spinal cord injury occurred in 11 patients; 3 patients had an ASIA grade $\mathrm{C}$ and 8 patients had an ASIA grade D. None of the patients in either group demonstrated neurological deterioration after surgical treatment or neurological improvement at the time of discharge. The 3-month followup results revealed at least one grade of improvement in the AISA impairment grade for all patients in both groups who had neurological impairment (Table 2). No further improvement was seen at the 12-month follow-up.

\section{Surgery}

Open multilevel posterior fusion surgery was performed in all patients, with a mean of $6.7 \pm 1.4$ levels fused in the AS group and $7.1 \pm 1.1$ levels fused in the OS group ( $p>0.05)$ (Tables 2 and 3). Three patients in the OS group required partial vertebrectomy with anterior column augmentation using a posterior approach. The mean intraoperative blood loss in the AS group was $584.1 \pm 196.0 \mathrm{ml}$ (range 300-1000 ml). In the OS group, the mean intraoperative blood loss was $570.8 \pm 207.4 \mathrm{ml}$ 
TABLE 4. Clinical course in the AS group versus the OS group

\begin{tabular}{lccc}
\hline \multicolumn{1}{c}{ Parameter } & $\begin{array}{c}\text { AS Group } \\
(\mathrm{n}=22)\end{array}$ & $\begin{array}{c}\text { OS Group } \\
(\mathrm{n}=24)\end{array}$ & $\mathrm{p}$ Value \\
\hline Mean LOS, days & $11.5 \pm 7.8$ & $8.4 \pm 3.3$ & $>0.05$ \\
\hline Mean ICU stay & $3.8 \pm 4.7$ & $1.3 \pm 1.2$ & $\mathbf{0 . 0 1}$ \\
\hline Mortality & & & \\
\hline$\quad$ In-hospital mortality & $2(9.1)$ & 0 & $>0.05$ \\
\hline 90-day mortality & $8(36.4)$ & 0 & $<0.001$ \\
\hline
\end{tabular}

Values are reported as number (\%) or mean \pm SD. Boldface type indicates statistical significance.

(range 200-1000 $\mathrm{ml}$ ). The mean surgical duration in the AS group was $226.5 \pm 82.5$ minutes and $240 \pm 51.2$ minutes in the OS group. No significant difference in terms of intraoperative blood loss and surgical duration was found between the two groups $(\mathrm{p}>0.05)$ (Table 3$)$. Epidural hematoma was noted intraoperatively in 14 patients $(64 \%)$ in the AS group compared with 3 patients $(13 \%)$ in the OS group ( $\mathrm{p}>0.05)$.

\section{LOS and ICU Stay}

Hospital and ICU stays were longer for patients with AS than for patients with osteoporotic fractures (11.5 \pm 7.8 days and $3.8 \pm 4.7$ days vs $8.4 \pm 3.3$ days and $1.3 \pm$ 1.2 days, respectively). A significantly longer ICU stay was seen in the AS group $(\mathrm{p}=0.01)$ (Table 4$)$.

\section{Complications}

Intraoperative complications developed in 3 patients in the AS group (dural tear) compared with 1 patient in the OS group (Table 3). No complications were noted in 9 patients in the AS group and 14 patients in the OS group. One patient in each group was readmitted within 30 days due to deep wound infection requiring surgical debridement. Minor complications developed in 8 patients (36\%) in the AS group and 9 patients (38\%) in the OS group during the early postoperative phase (Table 5); all of these patients could be treated successfully using conservative methods. Ten patients (45\%) in the AS group developed major complications compared with 4 patients $(17 \%)$ in the OS group. Four patients (18\%) in the AS group and 3 patients (13\%) in the OS group had both minor and major complications. No significant difference was found in terms of minor complication rates between groups ( $\mathrm{p}>$ $0.05)$. In terms of total major complications, a significant difference was found between the two groups $(\mathrm{p}=0.03)$ (Table 5).

\section{Mortality}

Two patients (9\%) in the AS group died within a few days of surgery due to a perforated viscus (bowel perforation) (Fig. 3). In-hospital mortality was not noted in the OS group. At 90 days postoperatively, another 6 patients in the AS group died due to acute renal failure $(n=1)$, acute respiratory failure $(n=1)$, myocardial infarction $(n=2)$, gastrointestinal bleeding $(\mathrm{n}=1)$, and bowel perforation ( $\mathrm{n}$ $=1)$ compared with none in the OS group. The overall 90-
TABLE 5. Ninety-day complication profile comparison between the AS group and the OS group

\begin{tabular}{|c|c|c|c|}
\hline \multirow[b]{2}{*}{ Complication } & \multicolumn{2}{|c|}{ No. of Pts (\%) } & \multirow[b]{2}{*}{$p$ Value } \\
\hline & $\begin{array}{l}\text { AS Group } \\
(\mathrm{n}=22)\end{array}$ & $\begin{array}{l}\text { OS Group } \\
(\mathrm{n}=24)\end{array}$ & \\
\hline \multicolumn{4}{|l|}{ Major complications } \\
\hline Deep wound infection & $1(5)$ & $1(4)$ & \\
\hline Acute respiratory failure & $1(5)$ & $1(4)$ & \\
\hline Myocardial infarction & $1(5)$ & 0 & \\
\hline Acute heart failure & 0 & $1(4)$ & \\
\hline Acute renal failure & $1(5)$ & $1(4)$ & \\
\hline Gastrointestinal bleeding & $2(9)$ & 0 & \\
\hline Bowel perforation & $4(18)$ & 0 & \\
\hline Total no. of pts & 10 & 4 & 0.03 \\
\hline \multicolumn{4}{|l|}{ Minor complications } \\
\hline Delirium & $2(9)$ & $1(4)$ & \\
\hline Acute encephalopathy & 0 & $1(4)$ & \\
\hline Dysphagia & $1(5)$ & $1(4)$ & \\
\hline Pleural effusion & 0 & $1(4)$ & \\
\hline Pneumonia & $1(5)$ & $1(4)$ & \\
\hline Urinary tract infection & $1(5)$ & $1(4)$ & \\
\hline Urinary retention & $2(9)$ & $2(8)$ & \\
\hline Deep vein thrombosis & $1(5)$ & 0 & \\
\hline lleus & 0 & $1(8)$ & \\
\hline Total no. of pts & 8 & 9 & $>0.05$ \\
\hline
\end{tabular}

Four patients in the AS group and 3 patients in the OS group had $>1$ complication. Boldface type indicates statistical significance.

day mortality in the AS group was $36 \%$ compared with $0 \%$ in the OS group, which reached statistical significance $(\mathrm{p}<0.001)$ (Table 5).

\section{Discussion}

With an increasing elderly population, the prevalence of patients older than 80 years of age is also rising. ${ }^{20} \mathrm{In}$ Europe, it is estimated that the number of people older than 80 years of age will double in the next 25 years. ${ }^{20}$ With this changing demographic, a large portion of the healthcare infrastructure will be dedicated to a subset of the population, with limited resources for those requiring complex medical care. ${ }^{21} \mathrm{~A}$ study conducted in the United Kingdom concluded that age older than 80 years was a separate risk factor for postoperative complications in people undergoing both emergency and elective surgery. ${ }^{21,22}$ When elderly patients with AS present after lowenergy trauma, clinicians should be aware of a higher risk of spine fractures. ${ }^{4}$ Authors have reported a three- to sevenfold higher risk of spine fractures in patients with AS and estimate that the risk of having a spine fracture rises by $1.3 \%$ per year after the age of 45 years. ${ }^{6,23}$ Although patients older than 80 years of age are at increased risk of encountering adverse events after surgical treatment of spine fractures, ${ }^{8,24-26}$ rates of complications, morbidity, and mortality are even higher when AS is present among other baseline comorbidities. ${ }^{27-30}$ 


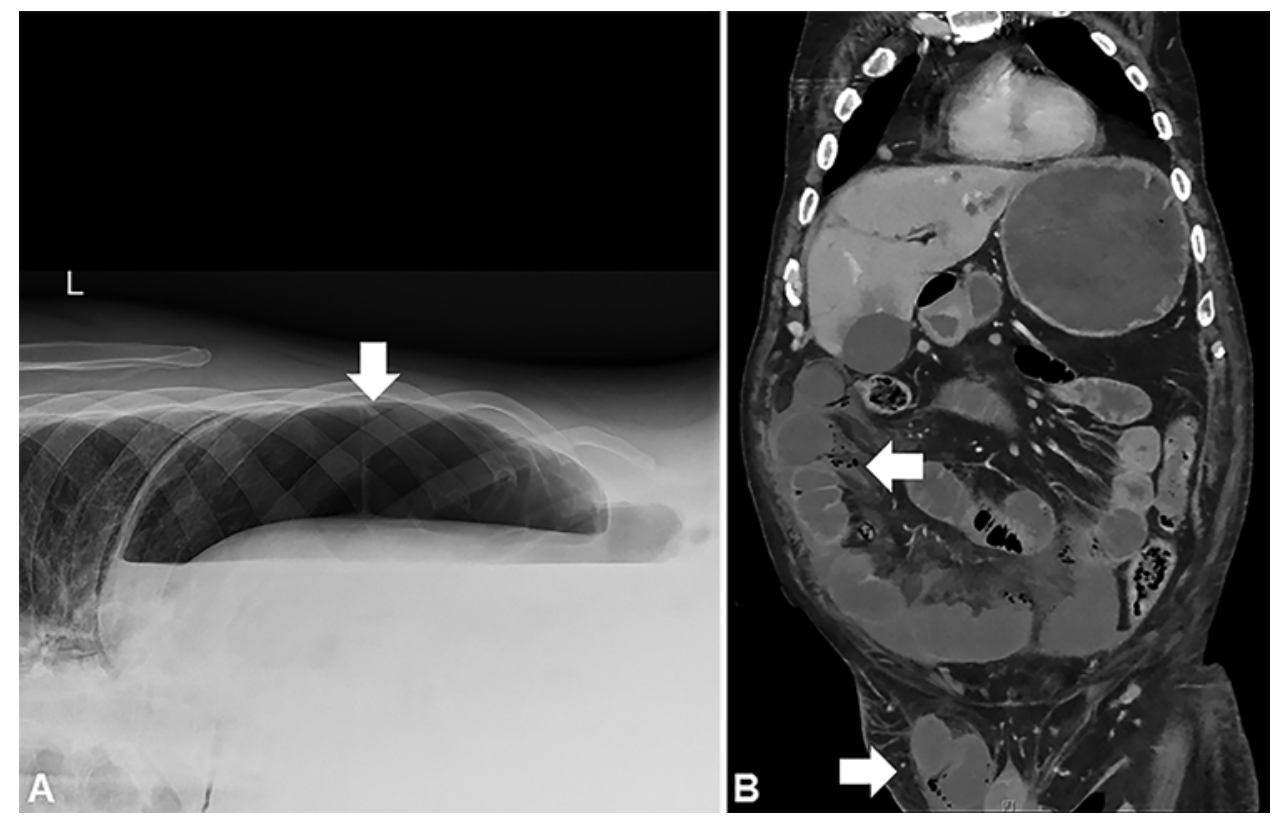

FIG. 3. A: An abdominal $x$-ray in the left lateral decubitus position revealed free intraperitoneal air (arrow) in an 87-year-old male who developed abdominal pain on the fifth postoperative day. Emergency laparotomy was performed which showed multiple bowel perforations with numerous gangrenous areas. A histological assessment confirmed Crohn's disease. The patient died of sepsis 2 days later in the ICU. B: An abdominal CT in an 83-year-old patient who complained of increasing abdominal pain and nausea on the 4th postoperative day showed an incarcerated inguinal hernia with bowel perforation and free abdominal air (arrows). The laboratory results revealed a high lactate level (> $4 \mathrm{mmol} / \mathrm{L})$ and elevated inflammatory parameters. An exploratory laparotomy was performed. The patient died within the same day of septic shock.

The aim of this study was to compare rates of early complications and 90-day mortality in patients older than 80 years of age with AS who received multilevel surgical fusion surgery for unstable fractures and compare the results with an age- and sex-matched cohort of patients with unstable osteoporotic fractures. Our results showed that patients with AS had a significantly higher incidence of comorbidity as reflected by the discrepant CCI scores. Low-energy trauma was the leading cause of injury in both groups. The surgical complication rate in the AS group was higher, with dural tears observed in 3 patients compared with 1 patient in the OS group. It is unclear whether these complications were primarily due to intraoperative puncture or occult traumatic tears due to fractures of the lamina, which have been described in patients with AS. ${ }^{31}$

As expected, a high postoperative complication rate was seen in both groups, with a significantly higher major complication rate in the AS group (45\% vs 17\%). We hypothesize that a higher proportion of comorbid conditions in the AS group may be associated with higher rates of complications. In the limited scope of this study, these findings may reflect an important trend in a highly vulnerable population that should be discussed with the patient and family prior to any intervention.

The overall 90-day mortality in surgically treated patients with AS was 36\% compared with $0 \%$ in the OS group. Of the 9 deaths documented, 5 were from gastrointestinal-related complications. Although postoperative gastrointestinal complications uniformly increase with age, the incidence of such complications may be higher in patients with AS than in the general elderly population.
The prevalence of inflammatory bowel disease has been described in up to $10 \%$ of patients with AS..$^{32}$ In 2 patients with bowel perforation, Crohn's disease and ulcerative colitis were histologically diagnosed.

\section{Review of the Literature}

In a series of elderly patients, Kobayashi et al. reported perioperative complications in $29 \%$ including $13 \%$ major complications. ${ }^{30}$ They found that age older than 85 years, blood loss more than $500 \mathrm{ml}$, and a surgical duration longer than 3 hours were significant risk factors. This study included different types of spine surgeries, from lumbar spinal stenosis to cervical spondylotic myelopathy; AS was not addressed.

In a large US database study (National [Nationwide] Inpatient Sample), Lukasiewicz et al. retrospectively analyzed 939 surgically treated patients with spinal fractures associated with $\mathrm{AS}^{29}$ Of those, 253 patients $(27 \%)$ were older than 80 years of age. Patients were treated either surgically or conservatively. The proportion of surgically treated patients in that study remains unclear. The overall inpatient mortality was $6.6 \%$. Nearly $30 \%$ of patients experienced an adverse event during the inpatient stay. ${ }^{29}$ Rudwaleit et al. found that around $5 \%$ to $10 \%$ of patients had an underlying inflammatory bowel condition and an even larger proportion of them presented with subclinical inflammation. ${ }^{33}$

Caron et al. retrospectively analyzed 122 patients with an inflammatory spinal disorder, of whom 28 patients (23\%) had AS. ${ }^{13}$ Surgical treatment, consisting of multi- 
level posterior instrumentation, was performed in $67 \%$ of patients. Complications during hospitalization developed in $84 \%$ of patients and were associated with a death rate of $32 \%$, which correlated with older age and a greater number of comorbidities.

In 2017, Bredin et al. published a multicentric retrospective study of 31 patients with AS in whom percutaneous multilevel screw fixation was performed to treat thoracolumbar fractures. ${ }^{34}$ The mean age at surgery was 75 years, and an in-hospital mortality of $9.6 \%$ was reported. Complications were not described, except for 1 patient (3.2\%) who required blood transfusion due to anemia after percutaneous screw fixation.

In a study by Westerveld et al., 14 surgically treated patients with AS with a mean age of 69 years were retrospectively analyzed..$^{10}$ At least one complication was reported in $87.5 \%$ of patients. The in-hospital mortality rate was $7.1 \%$.

Vazan et al. recently published a retrospective case series of 41 patients with ankylosing spinal disease with a mean age of 73 years. ${ }^{9}$ Of those, 24 patients $(58.5 \%)$ had AS. The overall complication rate in the study was $48.8 \%$ and 5 patients (12.2\%) died during hospitalization.

\section{Limitations}

The current study has several limitations, many of which are associated with the retrospective design and the limited number of patients in each cohort. We did not identify the subtypes of AS, which might have an influence on the clinical outcome. Furthermore, the kinetic energy required to create an unstable fracture may differ between groups, which potentially could have influenced the results. The minimum follow-up period of 12 months is relatively short, and, by gathering long-term data, other relevant findings not captured in the current study might be revealed. Furthermore, minimally invasive stabilization procedures for AS were not included. Due to a high rate of neurological deficits (46\%) and epidural hematomas (64\%) in the AS group, surgeons preferred to perform an open procedure with multilevel laminectomies. However, this study is unique in that it presents one of the few investigations of surgically treated AS in a population of patients older than 80 years of age. Larger studies are needed to further investigate the trends seen in our patient population.

\section{Conclusions}

Due to a steadily increasing average life expectancy, spinal surgeons will be frequently confronted with elderly patients requiring surgical treatment. The results of this and previous studies show that high complication rates are associated with treatment of patients older than 80 years of age with AS, whether they are surgically or nonsurgically treated. Despite a high morbidity and mortality, we still recommend that multilevel posterior stabilization should be considered for unstable fractures in patients with AS, although the risks should be clearly discussed with the patient and relatives. We hope that this study can help to develop a consensus about the best treatment strategy for unstable fractures in patients with AS older than 80 years of age.

\section{References}

1. Braun J, Sieper J. Ankylosing spondylitis. Lancet. 2007; 369(9570):1379-1390.

2. Kubiak EN, Moskovich R, Errico TJ, Di Cesare PE. Orthopaedic management of ankylosing spondylitis. J Am Acad Orthop Surg. 2005;13(4):267-278.

3. Ghozlani I, Ghazi M, Nouijai A, Mounach A, Rezqi A, Achemlal L, et al. Prevalence and risk factors of osteoporosis and vertebral fractures in patients with ankylosing spondylitis. Bone. 2009;44(5):772-776.

4. Trent G, Armstrong GW, O'Neil J. Thoracolumbar fractures in ankylosing spondylitis. High-risk injuries. Clin Orthop Relat Res. 1988;227(227):61-66.

5. Feldtkeller E, Vosse D, Geusens P, van der Linden S. Prevalence and annual incidence of vertebral fractures in patients with ankylosing spondylitis. Rheumatol Int. 2006;26(3):234239.

6. Vosse D, Feldtkeller E, Erlendsson J, Geusens P, van der Linden S. Clinical vertebral fractures in patients with ankylosing spondylitis. J Rheumatol. 2004;31(10):1981-1985.

7. Einsiedel T, Schmelz A, Arand M, Wilke HJ, Gebhard F, Hartwig E, et al. Injuries of the cervical spine in patients with ankylosing spondylitis: experience at two trauma centers. $J$ Neurosurg Spine. 2006;5(1):33-45.

8. Gerhardt J, Bette S, Janssen I, Gempt J, Meyer B, Ryang YM. Is eighty the new sixty? Outcomes and complications after lumbar decompression surgery in elderly patients over 80 years of age. World Neurosurg. 2018;112:e555-e560.

9. Vazan M, Ryang YM, Barz M, Török E, Gempt J, Meyer B. Ankylosing spinal disease-diagnosis and treatment of spine fractures. World Neurosurg. 2019;123:e162-e170.

10. Westerveld LA, van Bemmel JC, Dhert WJ, Oner FC, Verlaan JJ. Clinical outcome after traumatic spinal fractures in patients with ankylosing spinal disorders compared with control patients. Spine J. 2014;14(5):729-740.

11. Schiefer TK, Milligan BD, Bracken CD, Jacob JT, Krauss WE, Pichelmann MA, Clarke MJ. In-hospital neurologic deterioration following fractures of the ankylosed spine: a single-institution experience. World Neurosurg. 2015;83(5): 775-783.

12. Rustagi T, Drazin D, Oner C, York J, Schroeder GD, Vaccaro AR, et al. Fractures in spinal ankylosing disorders: a narrative review of disease and injury types, treatment techniques, and outcomes. J Orthop Trauma. 2017;31(suppl 4):S57-S74.

13. Caron T, Bransford R, Nguyen Q, Agel J, Chapman J, Bellabarba C. Spine fractures in patients with ankylosing spinal disorders. Spine (Phila Pa 1976). 2010;35(11):E458-E464.

14. Werner BC, Samartzis D, Shen FH. Spinal fractures in patients with ankylosing spondylitis: etiology, diagnosis, and management. J Am Acad Orthop Surg. 2016;24(4):241-249.

15. General Assembly of the World Medical Association. World Medical Association Declaration of Helsinki: ethical principles for medical research involving human subjects. J Am Coll Dent. 2014;81(3):14-18.

16. Wang YF, Teng MM, Chang CY, Wu HT, Wang ST. Imaging manifestations of spinal fractures in ankylosing spondylitis. AJNR Am J Neuroradiol. 2005;26(8):2067-2076.

17. Wade SW, Strader C, Fitzpatrick LA, Anthony MS, O'Malley CD. Estimating prevalence of osteoporosis: examples from industrialized countries. Arch Osteoporos. 2014;9:182.

18. de Groot V, Beckerman H, Lankhorst GJ, Bouter LM. How to measure comorbidity. a critical review of available methods. J Clin Epidemiol. 2003;56(3):221-229.

19. Deyo RA, Cherkin DC, Ciol MA. Adapting a clinical comorbidity index for use with ICD-9-CM administrative databases. J Clin Epidemiol. 1992;45(6):613-619.

20. Kotzeva M. Eurostat regional yearbook 2016. Accessed August 2, 2021. https://ec.europa.eu/eurostat/en/web/productsstatistical-books/-/KS-HA-16-001 
21. Chibbaro S, Di Rocco F, Makiese O, Mirone G, Marsella M, Lukaszewicz AC, et al. Neurosurgery and elderly: analysis through the years. Neurosurg Rev. 2010;34(2):229-234.

22. Wilkinson K. An age-old problem: care of older people undergoing surgery. Br J Hosp Med (Lond). 2011;72(3):126-127.

23. Cooper C, Carbone L, Michet CJ, Atkinson EJ, O'Fallon WM, Melton LJ III. Fracture risk in patients with ankylosing spondylitis: a population based study. J Rheumatol. 1994 21(10):1877-1882.

24. Ishak B, Schneider T, Gimmy V, Unterberg AW, Kiening KL. Early complications, morbidity, and mortality in octogenarians and nonagenarians undergoing posterior intra-operative spinal navigation-based $\mathrm{C} 1 / 2$ fusion for type II odontoid process fractures. J Neurotrauma. 2017;34(24):3326-3335.

25. Kobayashi K, Imagama S, Ando K, Ishiguro N, Yamashita $\mathrm{M}$, Eguchi $\mathrm{Y}$, et al. Risk factors for delirium after spine surgery in extremely elderly patients aged 80 years or older and review of the literature: Japan Association of Spine Surgeons with Ambition multicenter study. Global Spine J. 2017;7(6): 560-566.

26. Bydon M, Abt NB, De la Garza-Ramos R, Olorundare IO, McGovern K, Sciubba DM, et al. Impact of age on short-term outcomes after lumbar fusion: an analysis of 1395 patients stratified by decade cohorts. Neurosurgery. 2015;77(3):347354.

27. Puvanesarajah V, Cancienne JM, Shimer AL, Shen FH, Hassanzadeh H. Complications after fusion for thoracolumbar fractures in patients with ankylosing spondylitis. Global Spine J. 2017;7(1):28-32.

28. Reinhold M, Knop C, Kneitz C, Disch A. Spine fractures in ankylosing diseases: recommendations of the Spine Section of the German Society for Orthopaedics and Trauma (DGOU). Global Spine J. 2018;8(2)(suppl):56S-68S.

29. Lukasiewicz AM, Bohl DD, Varthi AG, Basques BA, Webb ML, Samuel AM, Grauer JN. Spinal fracture in patients with ankylosing spondylitis: cohort definition, distribution of injuries, and hospital outcomes. Spine (Phila Pa 1976). 2016; 41(3):191-196.

30. Kobayashi K, Imagama S, Ando K, Ishiguro N, Yamashita $\mathrm{M}$, Eguchi $\mathrm{Y}$, et al. Complications associated with spine surgery in patients aged 80 years or older: Japan Association of Spine Surgeons with Ambition (JASA) multicenter study. Global Spine J. 2017;7(7):636-641.
31. Li KK, Chung OM, Chang YP, So YC. Myelopathy caused by ossification of ligamentum flavum. Spine (Phila Pa 1976). 2002;27(12):E308-E312.

32. Moltó A, Nikiphorou E. Comorbidities in spondyloarthritis. Front Med (Lausanne). 2018;5:62.

33. Rudwaleit M, Baeten D. Ankylosing spondylitis and bowel disease. Best Pract Res Clin Rheumatol. 2006;20(3):451-471.

34. Bredin S, Fabre-Aubrespy M, Blondel B, Falguières J, Schuller S, Walter A, et al. Percutaneous surgery for thoraco-lumbar fractures in ankylosing spondylitis: study of 31 patients. Orthop Traumatol Surg Res. 2017;103(8):1235-1239.

\section{Disclosures}

Dr. Roh: ownership in IntuitiveX, Amplify Surgical, Carlsmed, and J\&J DePuy Synthes; and consultant for Stryker. Dr. Oskouian: royalties from Stryker and Globus. Dr. Chapman: consultant for Globus Medical and editor in chief of Global Spine Journal.

\section{Author Contributions}

Conception and design: Ishak, Oskouian, Chapman. Acquisition of data: Ishak, Frieler, von Glinksi, Blecher, Strot. Analysis and interpretation of data: Ishak. Drafting the article: Ishak. Critically revising the article: Rustagi, Unterberg, Roh, Hart, Oskouian, Chapman. Reviewed submitted version of manuscript: Rustagi, von Glinksi, Roh, Hart, Oskouian, Chapman. Approved the final version of the manuscript on behalf of all authors: Ishak. Statistical analysis: Norvell. Administrative/technical/material support: Strot. Study supervision: Oskouian, Chapman.

\section{Supplemental Information Videos}

Video Abstract. https://vimeo.com/597118649.

\section{Correspondence}

Basem Ishak: University of Heidelberg, Germany.basem.ishak@ hotmail.com. 